\title{
Mood, Side-effects and Smoking Outcomes Among Persons With and Without Probable Lifetime Depression Taking Varenicline
}

Jennifer B. McClure, $P h D^{7}$, Gary E. Swan, $P h D^{2}$, Lisa Jack, $M A^{2}$, Sheryl L. Catz, PhD ${ }^{7}$, Susan M. Zbikowski, PhD ${ }^{3}, \operatorname{Tim}$ A. McAfee, MD, MPH ${ }^{3}$, Mona Deprey, $\mathrm{MS}^{3}$, Julie Richards, $\mathrm{MPH}^{7}$, and Harold Javitz, $P h D^{2}$

${ }^{1}$ Group Health Center for Health Studies, Seattle, WA, USA; ${ }^{2}$ SRI International, Menlo Park, CA, USA; ${ }^{3}$ Free \& Clear, Inc, Seattle, WA, USA.

$\mathrm{J}$ Gen Intern Med 24(10):1173

DOI: $10.1007 / \mathrm{s} 11606-009-0966-0$

(c) Society of General Internal Medicine 2009

T $\mathrm{n}$ the original publication, the abstract incorrectly states

1 treatment side-effects and outcomes were compared at

2 days after the target quit date. The correct timing is 21 days.

The authors regret this error.

The online version of the original article can be found at $h$ ttp://dx.doi. org/10.1007/s11606-009-0926-8

Published online April 4, 2009 